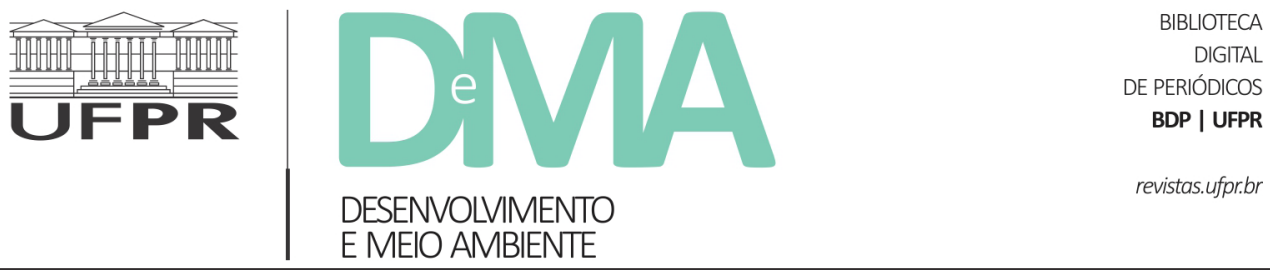

\title{
Interfaces entre o debate colonial e os estudos de jornalismo ambiental
}

\section{Interfaces between colonial debate and environmental journalism studies}

\author{
Eloisa Beling LOOSE ${ }^{1 *}$, Ilza Maria Tourinho GIRARDI ${ }^{1}$ \\ ${ }^{1}$ Universidade Federal do Rio Grande do Sul (UFRGS), Porto Alegre, RS, Brasil. \\ ${ }^{*}$ E-mail de contato: eloisa.beling@gmail.com
}

Ensaio recebido em 16 de agosto de 2020, versão final aceita em 16 de fevereiro de 2021, publicado em 7 de outubro de 2021.

RESUMO: $\quad$ Este ensaio, fruto de pesquisa bibliográfica, tem como objetivo tensionar os pressupostos do jornalismo ambiental com o debate colonial, sobretudo a partir da perspectiva do meio ambiente. Entende-se o jornalismo ambiental como uma prática engajada que ultrapassa uma especialização temática, colocando em evidência as problemáticas ambientais e questionando aspectos consolidados dentro do campo jornalístico, oriundos de uma lógica eurocêntrica. Pretende-se apontar as interfaces do jornalismo com a discussão ambiental a partir das abordagens críticas ao colonialismo. Dentre as considerações, verifica-se que, mesmo sem mencionar de forma explícita as correntes teóricas que discutem a questão colonial, o jornalismo ambiental incorpora esta crítica desde o início ao entender a natureza na sua inteireza e a humanidade como parte dela.

Palavras-chave: jornalismo; colonialidade; meio ambiente.

ABSTRACT: This essay, result of bibliographic research, aims to tension the assumptions of environmental journalism with the colonial debate, especially from the perspective of the environment. Environmental journalism is understood as an engaged practice that goes beyond a thematic specialization, highlighting environmental issues and questioning consolidated aspects within the journalistic field, arise from a Eurocentric logic. It's intended to point out the interfaces of journalism with the environmental discussion from the critical approaches to colonialism. Among the considerations, it appears that, even without explicitly mentioning the theoretical currents that discuss the colonial issue, environmental journalism incorporates this criticism from the beginning by understanding nature in its entirety and humanity as part of it.

Keywords: journalism; coloniality; environment. 


\section{Introdução}

Compreende-se o jornalismo ambiental (JA), de maneira geral, como uma especialização temática dentro do jornalismo, entendido como uma forma de conhecimento (Meditsch, 1997), que está em tensão constante entre seu polo ideológico, alinhado com seu papel social de servir ao interesse público, e seu polo econômico (Traquina, 2005), atrelado ao contexto comercial, que vê as notícias como mercadorias; portanto, foca seus esforços naquilo que dá mais audiência e, consequentemente, lucro às empresas midiáticas. Ainda que as normas e bases epistemológicas das diferentes especializações jornalísticas (jornalismo esportivo, político e econômico, por exemplo) não costumem variar, o espaço de trocas entre o campo jornalístico e o campo ambiental fez eclodir um jornalismo engajado com a sustentabilidade da vida'(Leff, 2016), com caráter interdisciplinar e que considera uma série de elementos que dificilmente se fazem presentes em outros tipos de jornalismo. Logo, o JA extravasa uma especialidade temática, trazendo para a prática jornalística novas lentes para observar a relação sociedade-natureza, apropriando-se de uma racionalidade ambiental (Leff, 2001) e trabalhando para transversalizar a pauta.

Ao refletir sobre a reconfiguração do campo comunicacional, do qual faz parte o jornalismo, a partir da epistemologia ambiental, Loose \& Souza-Lima (2013) destacam que no JA o meio ambiente não é apenas objeto de narração, divulgação ou produção noticiosa, mas há uma perspectiva diferenciada que considera o pluralismo, a diversidade, a complexidade das relações que perpassam a esfera ambiental e o próprio saber ambiental na sua elaboração. Além disso, “[...] precisa ter um caráter revolucionário, comprometido com a mudança de paradigmas, deve enxergar além das aparências e não ser complacente com aqueles que se apropriaram da temática ambiental para formar ou reforçar a imagem" (Loose \& Souza-Lima, 2013, p. 67), suspeitando das soluções milagrosas e trabalhando para desvendar as ligações de interesses presentes nas problemáticas ambientais. Girardi et al. (2011, p. 109) ressaltam que "[...] a ideia de transformar uma sociedade alheia aos seus problemas em uma sociedade com cidadania ambiental norteia os rumos do jornalismo ambiental".

Entretanto, para que o JA consiga exercer seu papel, de acordo com os pressupostos colocados, é preciso que se descolonialize a prática, rompendo com a lógica hegemônica do pensamento científico binário e cartesiano, que fragmenta os conhecimentos, presente não apenas nas redações e outros espaços de trabalho, mas nas universidades e demais espaços de formação ${ }^{2}$. O jornalismo tem papel relevante nesse processo, pois faz circular os discursos na sociedade, permitindo que, por meio do seu fazer, diferentes atores sociais tenham conhecimento do que grupos específicos estão fazendo. Meditsch (1997, p.3) afirma: "O Jornalismo não apenas reproduz o conhecimento que ele próprio produz, reproduz também o conhecimento produzi-

\footnotetext{
${ }^{1}$ Expressão usada por Leff (2016) para dar conta da daquilo que os povos chamam de "viver bem", vivir bien”, "bien vivir", buen vivir" e outros termos que refletem a diversidade dos modos de existência dos povos da Terra. "Sustentabilidade da vida" remete a essa compreensão do mundo que é oposta à sustentabilidade possível dentro do quadro da modernidade.

${ }^{2}$ Para aprofundar a discussão da descolonização, ver Maldonado-Torres (2007) e Castro-Gómez (2007).
} 
do por outras instituições sociais". Dessa forma, ao seguir a lógica dualista ou reconhecer apenas como fontes os atores sociais legitimados pelo pensamento do Norte Global (geralmente as chamadas fontes oficiais, detentoras de um conhecimento científico reconhecido pelos pares), o jornalismo colabora para manutenção de uma forma de ver colonizada.

Este ensaio, baseado em pesquisa bibliográfica (Gil, 2002) a partir de buscas pela combinação dos conceitos-chave $^{3}$ desse texto, objetiva tensionar as relações entre jornalismo, meio ambiente e questão colonial, de modo a verificar pontos de convergência e limites entre si. Busca-se evidenciar como o JA possui alguma abertura para amplificar o questionamento colonial e dar espaço para outras formas de viver e se relacionar com a natureza. Parte-se da hipótese de que a discussão epistemológica realizada ao longo dos últimos dez anos, no âmbito do Grupo de Pesquisa Jornalismo Ambiental da Universidade Federal do Rio Grande do Sul, já está, em muitos aspectos, alinhada com a quebra das monoculturas (do conhecimento rigoroso, das classificações naturais, do tempo linear, da escala e da produtividade), que geram a sociologia das ausências (Sousa Santos, 2002). Avalia-se que conceitos presentes na abordagem das Epistemologias do Sul (Sousa Santos \& Meneses, 2010) já estavam presentes na concepção do JA, como, por exemplo, a ecologia dos saberes, e que a discussão sobre a colonialidade a partir da subjugação da natureza fortalece os pressupostos da área.

\section{Questão colonial: assimetrias e violências persistentes}

Ainda que o colonialismo, regime de poder instalado por ocasião dos processos históricos de colonização, tenha se extinguido na maioria dos territórios, a colonialidade, herança desse processo, que mantém, em diferentes âmbitos sociais, relações de poder assimétricas, permanece presente até os dias de hoje. Apesar das independências, o mundo pós-colonial continua a viver sob a matriz colonial de poder ${ }^{4}$ (Green, 2014), o que significa a perpetuação das estruturas mentais e materiais de dominação. Lander (2005) afirma que, apesar de serem mobilizados recursos históricos diferentes - a evangelização, a civilização, a modernização até a globalização -, prossegue a ideia que há um padrão civilizatório, entendido naturalmente como superior e normal - o europeu -, que deveria ser universalizado.

Ao se colocar relevo na questão colonial, objetiva-se apontar a dominação epistemológica que acarretou a supressão de muitas formas de saber e ser, de modo a privilegiar o pensamento eurocêntrico, do colonizador, que se tornou único. Sousa Santos (2010) chama esse pensamento moderno ocidental de abissal, composto por distinções visíveis e invisíveis que separam de forma radical aquilo validado e respeitado pelo Ocidente em prejuízo de outras formas de conceber e existir no mundo.

\footnotetext{
${ }^{3}$ Foram realizadas pesquisas na Biblioteca Digital Brasileira de Teses e Dissertações do Instituto Brasileiro de Informação, Ciência e Tecnologia, no Google Acadêmico, no Catálogo de Teses e Dissertações da Capes e no Portal de Periódicos da Capes, com uma série de combinações entre as expressões: "jornalismo", "meio ambiente", "decolonial" e "colonial".

${ }^{4}$ Conceito cunhado originalmente por Aníbal Quijano, a matriz colonial de poder parte de quatro domínios inter-relacionados: 1) controle da economia, 2) da autoridade, 3) do gênero e da sexualidade, e 4) do conhecimento e da subjetividade, sendo sustentado pelo fundamento racial e patriarcal do conhecimento (Mignolo, 2017).
} 
Os estudos centrados na questão colonial emergem, de forma esparsa, nos anos 1950 e propõem uma nova forma de observar e fazer o mundo, que discute a hegemonia do pensamento presente no Sul Global. Vários grupos, com diferentes denominações ${ }^{5}$ (anticolonial, decolonial, pós-colonial, etc.), posicionam-se contra a ideia do pensamento único e homogeneizante, que desumaniza e oprime o outro em razão de seus interesses. Assim, tratar da questão colonial é admitir que a divisão Norte-Sul ${ }^{6}$ ainda influencia territórios e modos de ser e existir, pois há modelos de desenvolvimento e conhecimento que são considerados e validados, e outros não, de acordo com a perspectiva de quem detém poder econômico, político e social.

A opção decolonial não pretende ser a única, mas busca se afirmar como mais uma alternativa e coexistir com outras, revelando, assim, que não há apenas um caminho universal (Mignolo, 2017). Boaventura de Sousa Santos (2010), a partir das Epistemologias do Sul, sustenta que a compreensão do mundo é mais ampla que a imposta pelo mundo ocidental, que a diversidade do mundo é infinita, e que não há uma única teoria que consiga apreender tal diversidade. A crítica colonial visa desocultar os processos de produção e valoração de conhecimentos, assim como as relações de destruição, discriminação e subjugação, que foram naturalizadas a partir do colonialismo e capitalismo, fenômenos que atuam de forma conjunta, e apontar para as inúmeras possibilidades existentes que até então foram desconsideradas pelo pensamento dominante.

Porto-Gonçalves (2006, p.14), ao tratar da construção do sistema-mundo moderno-colonial, recorda que o surgimento da modernização se dá com a colonização, sendo "a descoberta da América decisiva para a consolidação da hegemonia européia no mundo [...] às custas de servidão, escravização, etnocídio, genocídio e ecocídio". O que depois foi chamado "processo de globalização" nasce dessa exploração, com distribuição desigual de proveitos e rejeitos, sendo que as relações predatórias atravessam a sociedade até hoje. Embora o autor separe por períodos o avanço da globalização, iniciando em 1492, é possível ver como as fases são sempre incorporadas ao modelo seguinte, sendo a colonialidade sempre insistente.

Martins \& Espinoza (2018) sublinham que a lógica do desenvolvimento hegemônico, calcada na racionalidade econômica moderna (Leff, 2001), que exclui a possibilidade da copresença dos dois lados da linha (Sousa Santos, 2007), se submete ao paradigma epistêmico colonial, obrigando agentes do Sul Global a seguir e aceitar aquilo que provém do Norte Global. Na mesma perspectiva, Cajigas-Rotundo (2007) afirma que a modernidade ${ }^{7}$ e a

\footnotetext{
${ }^{5} \mathrm{Na}$ América Latina destaca-se o projeto de investigação Modernidad/Colonialidad (M/C), que possui forte diálogo com as discussões do pós-colonialismo, estudos subalternos e a perspectiva de sistema-mundo, desenvolvida por Immanuel Wallerstein, e “[...] se organiza a partir de una crítica de base histórico-cultural y epistemológica de la modernidad, cuestionando las grandes narrativas interpretativas de la misma, a lo largo de cinco siglos" (Alimonda, 2011, p.23).

${ }^{6}$ Tal divisão não se dá em relação aos lugares geográficos, mas podem ser apreendidas como metáforas da exploração e marginalização. “O Sul é aqui concebido metaforicamente como um campo de desafios epistêmicos, que procuram reparar os danos e impactos historicamente causados pelo capitalismo na sua relação colonial com o mundo" (Sousa Santos \& Meneses, 2010, p.19).

${ }^{7}$ A modernidade é forjada no ideal cartesiano, que separa sujeito e objeto, homem e natureza, tendo como princípios "ideais" a razão universal, a liberdade social e os direitos individuais. (Leff, 2016).
} 
colonialidade são duas faces de uma mesma moeda, ou seja, integram um mesmo sistema que depende da distribuição assimétrica do poder e na extração sem limites dos territórios coloniais. Para Mignolo (2017), a colonialidade é o "lado mais escuro" da modernidade, que se origina na Europa, mas se expande globalmente. Já Alimonda (2011) destaca que a questão colonial pode ser considerada o seu fenômeno fundante.

A construção retórica da modernidade se mantém porque consegue atualizar seus mecanismos de dominação e exploração a partir de novos discursos, que, na verdade, são (re) formatados de modo a permitir que o sistema continue colonizando. No princípio, a modernidade representava a salvação religiosa, atuando a partir, principalmente, da conversão ao cristianismo, mas depois ela avançou sobre os não europeus sob o pretexto do progresso, do desenvolvimento, da modernização e até do estabelecimento da democracia. Para além da retórica, os fundamentos epistêmicos também sofreram mutações ao longo dos séculos: a teopolítica veio primeiro, depois a egopolítica e, por fim, o pensamento tecnológico (Mignolo, 2017).

Neste ensaio evidencia-se que a manutenção da colonialidade é sustentada também pela exploração do ambiente. "A colonização da natureza e a hegemonia do conhecimento eurocêntrico ${ }^{8}$ são processos complementares, já que estão no centro de uma disputa sobre o poder de nomeação da moderna crise ambiental" (Martins \& Espinoza, 2018 , p.104). Mais do que ser pano de fundo para a crítica colonial, assume-se, como Mignolo (2017, p.6), que a questão da natureza “[...] poderia também ser assinalada como o quinto domínio da matriz colonial, em vez de considerá-la como parte do domínio econômico". Dominar, explorar e conquistar o ambiente é algo fundamental para a manutenção da colonialidade até hoje.

\begin{abstract}
O desafio ambiental está no centro das contradições do mundo moderno-colonial. Afinal, a ideia de progresso e, sua versão mais atual, desenvolvimento é, rigorosamente, sinônimo de dominação da natureza! Portanto, aquilo que o ambientalismo apresentará como desafio é, exatamente, o que o projeto civilizatório, nas suas mais diferentes visões hegemônicas, acredita ser a solução: à ideia de dominação da natureza do mundo moderno-colonial, o ambientalismo coloca-nos diante da questão que há limites para a dominação da natureza (Porto-Gonçalves, 2006, p.61, grifos do autor).
\end{abstract}

Porto-Gonçalves (2006) destaca a natureza como aspecto nevrálgico no processo de expansão capitalista, pois é por meio dela que emerge a ideia de desenvolvimento, que escancara a ruptura que a humanidade faz com o meio ambiente: retira-se o envolvimento das partes. Depois, a globalização, que emerge da mesma racionalidade econômica, que observa natureza como recurso, também ocupa seu espaço, valorando aquilo que é internacional, aquilo que é mais rentável apartado dos modos de ser, existir e viver em cada território. Esse fenômeno renova o discurso da modernidade, dá saliência às questões globais, como as mudanças climáticas, e, consequentemente, estende essa escala para o que

\footnotetext{
${ }^{8}$ Importante dizer que o eurocentrismo não é uma questão de geografia, mas de epistemologia, como pontuam os autores que tratam da colonialidade. Concordando com Porto-Gonçalves (2005), a crítica ao eurocentrismo que permeia essa reflexão diz respeito à sua episteme e à lógica, que funciona por meio de reducionismos e separações.
} 
entende como soluções. Dessa maneira, a resolução desses problemas fica confiada e restrita aos políticos, empresários e especialistas, detentores de um conhecimento técnico-científico, calcado no conhecimento eurocêntrico. Outra estratégia relacionada a essa perspectiva está no apagamento das diferenças entre quem emite ou polui e quem é diretamente afetado pelas mudanças do clima:

[...] universalizar el problema del cambio climático sin evidenciar las importantes distinciones y responsabilidades entre países y grupos de personas que este implica, reduce la discusión y las posibles opciones de cambio a prácticas individuales de consumo, así como a cambios superficiales en los patrones de producción obscureciendo una discusión sobre la profunda desigualdad que está implícita en el cambio climático (Tornel, 2019, p.31).

Diferentemente do pensamento eurocêntrico, propagado (às vezes à força) pelos cristãos ocidentais, a ideia de natureza, para os povos tradicionais do Sul, não é oposta ou descolada do entendimento de cultura, exterior ao próprio ser humano. A Pachamama (Mãe Terra) funde cultura e natureza, mescla o interior com o exterior, e o material com o subjetivo. Dessa forma, segundo Mignolo (2017), ao implantar a concepção ocidental de natureza e descartar a de Pachamama, o colonialismo já estava sendo inserido no âmbito do conhecimento e da subjetividade.

\section{Meio ambiente colonizado}

Vive-se hoje uma crise ambiental sem precedentes, fruto de um "[...] modo hegemônico de entendimento do mundo" (Leff, 2016, p.25) próprio da modernidade. Os limites foram extrapolados e os impactos desse modelo explorador (centrado em crescimento econômico a qualquer custo) não se detêm em fronteiras, reagindo, até de forma não prevista, por gerações futuras.

En efecto, las crisis ambientales del pasado - en la Mesopotamia, en Mesoamérica, o en la cuenca del Mediterráneo - tuvieron un carácter local o regional, afectaron modalidades específicas de relación con la naturaleza, y se desarrollaron de manera gradual. La de nuestro tiempo, en cambio, tiene un alcance global; afecta a todas las modalidades contemporáneas de relación de los humanos con el mundo natural; se desarrolla con intensidad creciente; y además, se torna ya en una crisis ecológica a través de procesos como el desgaste de la capa de ozono, el calentamiento de la atmósfera, la pérdida de biodiversidad y la contaminación masiva del aire, el agua y los suelos del planeta (Castro Herrera, 2002, p.90).

Apesar de todos os indícios e previsões de que já chegamos em um ponto com impactos irreversíveis para a manutenção da vida, o modelo hegemônico insiste em avançar com o mesmo projeto extrativista e degradador do passado. Swampa (2019), ao conectar a questão climática com a expansão das commodities na América Latina, expõe a nossa dependência em relação ao Norte Global. Sob a lógica da colonialidade, o Sul continua sendo um local demasiado selvagem e bruto, que precisa ser domesticado por meio do pensamento tecnocrático que alimenta o capitalismo e converte a Mãe Terra em fragmentos para manutenção do poder estabelecido. Tal questão salienta o quanto o meio ambiente é uma questão-chave para o capitalismo e o colonialismo. 
Alimonda (2011), ao aproximar a Ecologia Política ${ }^{9}$ da História Ambienta ${ }^{10}$, ressalta a colonialidade que atinge a natureza latino-americana e os povos que nesse lugar vivem. Para o autor, a região é vista como subalterna e, portanto, à disposição dos regimes de acumulação vigentes. A fim de colonizar uma vez mais o território, o arcabouço técnico-científico-utilitarista eurocêntrico é mobilizado, legitimando uma racionalidade econômica que sirva aos interesses do Norte. De acordo com Atiles-Osoria (2013), o colonialismo ambiental já não se limita ao exercício do biopoder ${ }^{11}$ sobre $o$ território, incluindo uma estrutura sociopolítica e jurídica que dá viabilidade à exploração consentida da natureza e de quem ali vive.

A administração e o controle da natureza, sustentados pelo conhecimento técnico-científico ocidental, são expressões da colonialidade (Mignolo, 2017) que não podem ser ignorados. Unger (2001, p.28) recorda que "todos, até os mais subjugados, têm o poder de subjugar as forças da natureza", destacando a extensão e gravidade que recai sobre a exploração do meio ambiente.

Nesse sentido, Green (2014) recorda que o exercício do colonialismo não é algo que ocorre apenas entre países ditos "desenvolvidos" e aqueles chamados "em desenvolvimento". Na tentativa de viver como o Norte Global, as elites do Sul tendem a reproduzir o modelo ecodestrutivo e insustentável, reproduzindo a lógica da colonialidade internamente, o que faz com que sujeitos mais vulneráveis se tornem subservientes e recursos naturais do próprio território passem a ser explorados em favor de uma minoria. O colonialismo ambiental, dessa maneira, funciona como um sistema ideológico de exploração, operado de modo planificado, legitimado e com o consentimento das elites nacionais (Atiles-Osoria, 2013).

Ainda, segundo Green (2014), é esse alargamento de ações exploratórias sem fim que levará à autodestruição da espécie e à crise planetária, afinal, o crescimento contínuo, chamado de progresso ou desenvolvimento, depara-se com os limites do planeta onde vivemos. A racionalidade moderna forjou um mundo insustentável, repleto de injustiças e destruição. Contudo, a crença de que a técnica tudo resolverá, “[...] mediadora da nossa relação com a natureza" (Porto-Gonçalves, 2006, p.76.), segue encorajando a humanidade em busca de mais progresso, ainda que isso agrave sobremaneira as problemáticas ambientais. O pensamento tecnocrático é parte dessa ideologia capitalista que se enreda na colonialidade.

\footnotetext{
${ }^{9}$ Campo de conhecimento inter e transdisciplinar que reúne diferentes ênfases e tradições de pesquisa sobre ecologia e política. Para Alimonda (2011, p.46), compreende "[...] es el estudio de las articulaciones complejas y contradictorias entre múltiples prácticas y representaciones (incluyendo diferentes sistemas de conocimiento y dispositivos topológicos), a través de los cuales diversos actores políticos, actuantes en iguales o distintas escalas (local, regional, nacional, global) se hacen presentes, con efectos pertinentes y con variables grados de legitimidad, colaboración y/o conflicto, en la constitución de territorios y en la gestión de sus dotaciones de recursos naturales".

${ }^{10}$ Conforme Alimonda (2011, p.32), "[...] es el estudio de las interacciones entre sociedades humanas y el medio natural a lo largo del tiempo, y de las consecuencias que de ellas se derivan para ambos, incluyendo las interacciones naturales mediadas por los humanos, y las interacciones humanas mediadas por la naturaliza".

${ }^{11} \mathrm{O}$ exercício do biopoder sobre a natureza implica não apenas a exploração dos espaços físicos, dos recursos e das condições do clima, mas também a dominação dos corpos humanos subalternizados (Alimonda, 2011).
} 
O pensamento colonial reduz a natureza a recurso natural, gerando uma ruptura entre as relações sociedade-natureza existentes. Soma-se a isso o fato de que o conhecimento trazido pelo Norte Global promove a desvalorização e a negação das formas de existir e compreender o mundo daqueles que se percebem como parte do (e não externo ao) ambiente. Assim, o ambiente como problema é associado ao Outro enquanto falta ou ausência dos atributos oriundos da modernidade. Dessa forma, as soluções só podem emergir do Norte, recobertas pela possibilidade da salvação. Isso é verificável em documentos internacionais que proclamam que o Sul seja auxiliado na proteção de seus recursos por meio de transferência de financiamento e tecnologias do Norte (Espinoza, 2016).

O discurso técnico-científico, que goza de uma pretensa neutralidade e universidade, tem sido instrumentalizado para sustentar um sistema classificatório colonial, no qual o Sul Global é visto e entendido como não civilizado, como um espaço vazio e bruto a ser domesticado. Martins \& Espinoza (2018, p.92) ratificam como se dá esse processo:

O debate técnico acaba por assumir essa referência de modernidade na temática ambiental e, ao tomar esse papel, opera também como um elemento de marginalização das outras formas de percepção da temática. Ou, como bem aponta Leff (2017) acerca da racionalidade econômica moderna, trata-se de um sistema de construção da realidade que não pode ser desvinculado do processo de desumanização dos sujeitos portadores de saberes que não respondem (ou dialogam) com sua lógica.
Para além da mudança radical do sujeito com o seu lugar de existência, a separação da relação homem-natureza também redefiniu o conceito de trabalho. A desumanização dos homens, realizada a partir de uma episteme colonial, transformou-os em mercadorias - "[...] os trabalhos escravizado e assalariado tornaram-se naturalizados no processo de criar uma economia de acumulação, que é hoje reconhecida como mentalidade econômica capitalista” (Mignolo, 2017, p.7).

A crítica colonial é um chamado à reconstrução de um olhar mais heterogêneo, plural, cooperativo e dialógico sobre o lugar no qual vivemos. Para Leff (2016), descolonizar o Sul exige desconstruir o conhecimento do Norte a fim de permitir que novas compreensões do mundo, mais plurais, tenham espaço. Unger (1991), ainda que não fale diretamente sobre a questão colonial, expõe como o controle do corpo, da mente e do meio ambiente são vistos como manifestações do poderio da humanidade. De acordo com sua reflexão, existe um entendimento de que o homem é superior e de que a natureza serve aos interesses humanos, reforçando uma perspectiva antropocêntrica e utilitarista em relação ao ambiente. Porém, é possível observar de outro modo: “[...] a Natureza serve e atende ao homem não porque subalterna mas porque superior, porque tem para dar. Neste dar de $\mathrm{Si}$, a Natureza revela o Sagrado no seu aspecto maternal de nutrir e proporcionar vida" (Unger. 1991, p.90).

Além da crítica à visão eurocêntrica, é preciso, portanto, a revalorização dos conhecimentos locais, tradicionais, populares, até então depreciados e negados. Para tanto, Sousa Santos (2007) defende a ecologia de saberes ${ }^{12}$ e Leff (2001) o saber

\footnotetext{
${ }^{12}$ Sousa Santos (2010, p.57) explica que a ecologia de saberes, enquanto epistemologia pós-abissal, objetiva “[...] explorar a pluralidade interna
} 
ambienta ${ }^{13}$, ambas perspectivas que eclodem da criatividade e pluralidade dos povos que habitam os territórios do Sul e que contestam a supremacia da racionalidade moderna. Unger (1991) apresenta ainda a necessidade de pensar em rede, em conectar aquilo que a dinâmica produtivista da modernidade separou para melhor dominar. Para a autora, o pensamento ecologista expressa essa necessidade de considerarmos outros valores - e não apenas aqueles dominantes.

\section{Bases do jornalismo ambiental e pontos de convergência}

A compreensão do JA adotada aqui extrapola a ideia de especialização jornalística, partindo de pressupostos epistemológicos que mesclam o papel social do Jornalismo às características interdisciplinares do campo Ambiental (Loose \& Souza-Lima, 2013). A questão ambiental não é apenas um assunto ou pauta, mas uma espécie de lente com a qual compreendemos o lugar no qual estamos. Na prática jornalística, esse modo de observar e interagir altera a forma de selecionar os fatos, interpelar as fontes e escrever os relatos, pois considera que o modus operandi do jornalismo hegemônico é insuficiente e redutor, justamente por ser calcado na fragmentação, na simplificação e na priorização de fontes com poder econômico, político ou social segundo a perspectiva da modernidade. Girardi et al. (2012, p.147) destacam:

Compreendemos, deste modo, que em jornalismo ambiental tudo é informação, incluindo o próprio ambiente, o espaço e as diferentes manifestações que abriga. Este pressupõe uma prática que, partindo do tema ecológico, englobe os vários matizes nos quais este tema se desdobra, suas diversas tematizações possíveis, nas quais o jornalismo fala das e deixa falar as diferentes vozes.

Par dar conta da transversalidade e das múltiplas conexões que essa perspectiva viabiliza, adotam-se preceitos discutidos e consolidados na produção do Grupo de Pesquisa Jornalismo Ambiental. Girardi et al. (2018, p.7) assim sistematizam os elementos requeridos pelo JA:

1) Ênfase na contextualização na tentativa de expor as relações entre causas e consequências, assim como das articulações dos diferentes campos sociais; 2) Pluralidade de vozes com o intuito de romper com a lógica de construção baseada no pensamento único e dar visibilidade a um verdadeiro diálogo de saberes; 3) Assimilação do saber ambiental, que envolve de uma nova abordagem para a prática jornalística. Leff (2001) aponta que o saber ambiental é um contraponto à homogeneidade e à racionalidade dominante, presentes no jornalismo hoje; 4) Cobertura sistêmica e próxima à realidade do leitor-além de ser frequente, a produção jornalística ambiental deve permitir que as pessoas se sintam pertencentes a esse problema a

da ciência, isto é, das práticas científicas que se têm tornado visíveis através das epistemologias feministas e pós-coloniais e [...] promove a interação e a interdependência entre os saberes científicos e outros saberes, não científicos".

${ }^{13}$ Para Leff (2009, p.21), "a construção do saber ambiental implica uma desconstrução do conhecimento disciplinar, simplificador, unitário. Trata-se de um debate permanente frente a categorias conceituais e formas de entendimento do mundo que tem consolidado formas de ser e conhecer modeladas por um pensamento unidimensional que tem reduzido a complexidade para ajustá-la a uma racionalidade da modernidade 
fim de tomar atitudes que modifiquem o contexto; 5) Comprometimento com a qualificação da informação, ou seja, preocupação em construir notícias que desvelem as conexões entre economia, política, cultura, ambiente, etc., que nem sempre são visíveis, e indiquem soluções, saídas; e 6) Responsabilidade com a mudança de pensamento - o JA tem como missão colaborar para transformar o pensamento diante das injustiças e desigualdades ambientais que nos cercam.

Tais pressupostos, desenvolvidos ao longo de mais de dez anos, articulam saberes do jornalismo às leituras críticas sobre meio ambiente, incluindo autores como Fritjof Capra, Edgar Morin, Nancy Mangabeira Unger e Enrique Leff (Girardi, 2018). Diferencia-se jornalismo de/sobre meio ambiente do chamado jornalismo ambiental, entendendo que a mera cobertura de temas ambientais, sem a adoção da episteme ambiental, de uma visão ecológica e do comprometimento do jornalista com o cuidado à vida, não correspondem à prática consciente $\mathrm{e}$ transformadora que caracteriza o JA.

Nessa perspectiva, de construção de um jornalismo outro, que se distingua do fazer tradicional, o olhar primeiro sobre a prática jornalística deve ser fruto de uma descolonização do saber, do fomento de uma racionalidade ambiental (Leff, 2001) ou, de outra maneira, articulado à uma sociologia das emergências (Sousa Santos, 2002).

Frome (2008) adverte em sua obra que o JA parte de uma consciência diferente daquela predominante. "Ele é mais do que uma forma de fazer reportagens e escrever, mas uma forma de viver, de olhar para o mundo e para si próprio. Ele começa com um conceito de serviço social, dá voz à luta e às demandas e se expressa com honestidade, credibilidade e finalidade" (Frome, 2008, p. 60). Bueno (2007, p.17), um dos precursores da discussão no
Brasil, também sinaliza para o "[...] caráter revolucionário, comprometido com a mudança de paradigmas" que esse jornalismo carrega. Além disso, Bueno (2007) aponta três funções específicas do JA: a informativa, a pedagógica e a política, demonstrando que mais do que produzir conteúdo bem contextualizado, os interesses perpassam os campos da educação e da cidadania.

É por adotar essa postura engajada, de compromisso com a sustentabilidade da vida (Leff, 2016), que o JA não é imparcial ou neutro com questões que envolvem a degradação do lugar onde vivemos - assim como o jornalismo, de forma ampla, não o é (ou deveria ser) com temas que envolvem corrupção, escravidão e outros assuntos que violem a dignidade humana.

Para Sierra Caballero (2016, p.15), é preciso que se perceba os confrontos que tentam ser mascarados por meio do pensamento hegemônico entre meio ambiente e crescimento econômico: "Plantear toda crítica de la mediación periodística desde el problema ambiental pasa por el antagonismo contra la lógica del capital que captura la información, la vida social $y$, por supuesto, la naturaleza". O autor defende um jornalismo militante em prol da proteção da Pachamama (Mãe Terra), que acolha a justiça social e seja transversal.

Bueno (2007) assevera que o profissional precisa ser mesmo engajado, na medida em que desmascara os acordos e interesses do capitalismo. Oliveira (2017, p.209), mesmo não se detendo às especificidades do JA, defende que o jornalista deve tomar o partido dos segmentos sociais oprimidos e que isso "[...] não significa empunhar bandeiras na redação, mas procurar entender os fenômenos sociais dentro da perspectiva de que há essa relação de opressão e que é necessário superá-la”. É nesse 
sentido também que se assume um posicionamento a favor do interesse público (e o meio ambiente é, ou deveria ser, uma preocupação coletiva, que envolve a sobrevivência de todos).

Assim, é preciso no JA, de acordo com Mendes Pereira (2014, p.25), "[...] que o papel do jornalista se transmute radicalmente do lugar comum de 'mediador neutro'[...]", internalizado pelo jornalismo hegemônico em razão dos valores da modernidade, afinal essa ideologia da neutralidade serviu e ainda serve aos interesses capitalistas. Para a autora, o caminho de construção do JA ainda é longo, mas já é possível ver o jornalista como um "tradutor entre saberes" (Mendes Pereira, 2014), exigindo uma perspectiva intercultural e não binária, de modo a desestruturar a linha abissal (Sousa Santos, 2007).

O que parece mover jornalistas ambientais é a ideia de que se pode transformar nossa relação com o ambiente, de que não somos meros reféns de uma concepção única de mundo. Frome (2008) percebe o JA como uma forma de revelar aspectos que ultrapassem a visão econômica estreita, presa ao lucro, evidenciando que outros caminhos existem e são possíveis. A concepção originária do jornalismo, de prestar informações que possibilitem à autogovernação das pessoas (Kovach \& Rosenstiel, 2004), reveste-se, a partir do olhar ambiental, de uma missão para que os cidadãos assumam sua cidadania planetária (Bacchetta, 2000) de modo a participar e decidir sua forma de vida na Terra.

Embora o jornalismo tradicional ou hegemônico se consolide na modernidade e se articule a partir de seus princípios, é possível dizer que, ao longo do tempo, muitas práticas jornalísticas questionaram e criticaram sua prática, como, por exemplo, o chamado jornalismo alternativo, que defende que o serviço prestado não deve ser orientado pela lógica capitalista. Contudo, dentre as formas contestatórias de jornalismo, é o JA que, de maneira mais ampla, tenta desconstruir a epistemologia moderna, tentando dar visibilidade aos saberes e sujeitos não reconhecidos pelo pensamento técnico-científico e propondo um fazer jornalístico em prol da vida. Isso porque parte do entendimento de que "a crise ambiental é uma crise da razão, do pensamento, do conhecimento" (Leff, 2009, p.18) e percebe seu papel-chave para a emancipação social. Assim, a mediação jornalística é indissociável dessas muitas crises que envolvem o colonialismo e o capitalismo em suas múltiplas formas de dominação, sendo necessário uma revisão ampla.

La descolonización del saber y del poder informativo supone, como advertimos, decolonizar nuestras miradas en materia de ciencia, tecnología, innovación y desarrollo; que, directa o indirectamente, permean los procesos de modernización implícitos en el discurso ideológico de la destrucción creativa. Esta deconstrucción de los patrones y modelos de saber, ya discutidos cuando hablamos de la importancia del diálogo de saberes y la cultura indígena, debe comenzar por abrir líneas de reflexión, como el ecofeminismo y otras formas profundas de conexión con la naturaleza que el relato moderno del periodismo ha ocluido en los espacios públicos de habla (Sierra Cabellero, 2016, p.17).

É em função dessa interface forte com a questão ambiental, na qual pode-se dizer que o jornalismo se transmuta para questões para além de sua própria lógica, englobando outras formas de ver o mundo e compreendendo os limites impostos pelo pensamento moderno no exercício da profissão, que a crítica colonial também emerge, seja porque a natureza pode ser vista como um dos domínios da matriz colonial (Mignolo, 2017), seja porque 
as relações entre sociedade e natureza, centro da discussão do JA, são permeadas de processos que remontam à colonialidade. Acredita-se que salientar essa articulação possa expandir e aprofundar os estudos em ambas as áreas.

\section{Conexões ampliadas desde o Sul}

Identificou-se durante a pesquisa bibliográfica que os estudos atrelados à questão colonial realizam aproximações pontuais com o campo da Comunicação, do qual faz parte o Jornalismo, mas possuem forte relação com os pressupostos que sustentam o JA. Valencia Rincón (2012) atesta que os estudos da Comunicação e os estudos culturais - esses últimos partilhantes da crítica pós-colonial - por muito tempo trilharam caminhos convergentes no contexto latino-americano. A contestação a respeito do imperialismo e da dependência assim como do neodeterminismo tecnológico são pontos comuns, embora, para muitos pesquisadores decoloniais, predomine a visão simplista e maniqueísta da área, a partir de um viés funcionalista, desconsiderando, por exemplo, os processos de ressignificacão realizados pelas audiências.

Torrico Villanueva (2018) afirma que mesmo sendo o campo da Comunicação, do qual faz parte o Jornalismo, construído sob bases ocidentais, no contexto da expansão da modernidade, desde os anos 1960, na América Latina, há três elementos que perpassam o pensamento da área: a crítica ao establishment teórico e prático, a preocupação com o interesse público e as relações com um futuro democrático. Tais elementos aproximam-se do projeto decolonial, que conta com influências importantes como Antonio Pasquali, Paulo
Freire, Luis Ramiro Beltrán e Jesús Martín-Barbero, referências ainda atuais para desconstruir e propor alternativas à comunicação vertical e instrumentalizada, que é dominante.

No campo profissional isso também se reproduz. Oliveira (2017), ao tratar do fazer jornalístico, destaca que o surgimento da atividade está associado à consolidação da democracia, à emancipação dos sujeitos, ao esclarecimento (no sentido Iluminista), mas, ao passar pela fase da mercantilização, a atividade passa a ter uma lógica de entretenimento midiático e, a partir de 1980, passa a existir em um cenário de concentração global dos meios de comunicação, colaborando com a manutenção do status quo.

\begin{abstract}
A espetacularização da realidade transforma, silenciosamente, os critérios de noticiabilidade. É por essa razão que hoje é difícil articular ideias como o papel fiscalizador dos poderes, de defesa do interesse público e outros valores éticos da democracia com a atividade jornalística (Oliveira, 2017, p.113).
\end{abstract}

Essa mudança no que se entende por jornalismo é decorrente da pressão de forças capitalistas, que negam a ideia de mediação em benefício das imediaticidades que distraem. Há muitos tipos de silenciamento, que podem ser vistos como um mecanismo de opressão, frutos de "[...] um passado colonial, como uma perenidade de uma tradição marcada pelo patrimonialismo, colonialismo e escravismo" (Oliveira, 2017, p.182). Esses silenciamentos podem ser facilmente articulados às lógicas de produção de não existência, pontuadas por Sousa Santos (2002), que asseguram a manutenção da linha abissal. 
Diante disso, ratifica-se o ponto de partida da Comunicação/Jornalismo decolonial proposto por Torrico Villanueva (2018): a compreensão crítica do momento em que se começa a violência colonial, ou seja, quando a negação da humanidade de uns (desumanização) é imposta pela suposta superioridade de outros e há uma divisão abstrata entre Norte e Sul dentro das sociedades.

Fue entonces que se implantó la in-comunicación, la verticalidad dominadora que reprimió las culturas sometidas, acudió al genocidio, colonizó los imaginarios de los dominados, clasificó racialmente a los “inferiores" y fijó un patrón excluyente de producción de conocimiento (Quijano, 1992). (Torrico Villanueva, 2018, p.78).

Sendo assim, o olhar decolonial da Comunicação está centrado na busca por uma comunicação que humaniza. $\mathrm{O}$ aspecto ambiental não é trazido aqui, mas Loose \& Maéve Sobrinho (2018) já sinalizaram as muitas semelhanças existentes entre o jornalismo humanizado e o ambiental.

Face ao exposto, resgatar o histórico da comunicação latino-americana e ampliar o espaço para a abordagem do jornalismo ambiental são tentativas de evidenciar a crítica à sociologia das ausências ${ }^{14}$, proposta por Sousa Santos (2002), e romper com a linha abissal, permitindo que a função política do jornalismo atue em prol dos que até hoje são constantemente silenciados. Esses são movimentos a partir do jornalismo que se interconectam com a questão colonial.

O jornalismo hegemônico acaba atuando como instrumento a favor do capital e do pensamento colonial, mas outras formas divergentes, críticas e plurais, podem (e devem) coexistir. O jornalismo feito desde a perspectiva do Sul, como observado, já questiona várias lógicas impostas do Norte Global, mas a discussão sobre o papel-chave da dominação da natureza na continuidade da colonialidade nem sempre é evidenciada. Eis mais uma conexão que precisa ser visibilizada na prática jornalística dedicada ao ambiente.

A proposta do JA desenvolvida pelo Grupo de Pesquisa Jornalismo Ambiental, ainda que não tenha explicitamente se alinhado à questão colonial até agora, aproxima-se de seus autores e posicionamentos tentando denunciar as práticas predatórias ao ambiente, ocultadas ou naturalizadas pelo pensamento moderno. Os jornalistas ambientais afastam-se das premissas do jornalismo hegemônico, comprometendo-se com a sustentabilidade da vida (Leff, 2016) e com o respeito ao outro, à diversidade e à multiplicidade de saberes e seres. Mesmo ainda sendo um jornalismo que atua nas brechas do sistema, mobiliza-se para alertar as pessoas a respeito da crise ambiental posta e das saídas possíveis para vivermos de outro jeito.

\footnotetext{
${ }^{14}$ Sousa Santos (2002, p.246) se refere à uma perspectiva que tenta demonstrar que aquilo que não existe foi produzido para ser assim, como "[...] uma alternativa não-credível ao que existe", ou seja, é uma sociologia que elabora não existências por meio da desqualificação e da invisibilização, por exemplo.
} 


\section{Referências}

Alimonda, H. La colonialidad de la naturaleza - una aproximación a la ecología Política latinoamericana. In: Alimonda, H. (Coord.). La naturaleza colonizada - Ecología política y minería en América Latina. Buenos Aires: CLACSO, p. 21-60, 2011.

Atiles-Osoria, J. M. Colonialismo ambiental, criminalización y resistencias: las muevilizaciones puetoriqueñas por la justicia ambiental en el siglo XXI. Revista Crítica de Ciências Sociais, 100, 131-152, 2013.

Bacchetta, V. L. El periodismo ambiental. In: Bacchetta, V. L. (Coord.). Ciudadania planetaria: temas y desafios del periodismo ambiental. Montevideo: IFEJ, p.18-21, 2000.

Bueno, W. Comunicação, jornalismo e meio ambiente: teoria e pesquisa. São Paulo: Mojoara, 2007.

Cajigas-Rotundo, J. C. La biocolonialidad del poder: Amazonía, biodiversidad y ecocapitalismo. In: Grosfoguel, R; Castro-Gómez, S. (Eds). El giro decolonial: reflexiones para una diversidad epistémica más allá del capitalismo global. Bogotá: Siglo del Hombre, p. 169-194, 2007.

Castro-Gómez, S. Decolonizar la universidad. La hybris del punto cero y el diálogo de saberes. In: Grosfoguel, R; Castro-Gómez, S. (Eds.). El giro decolonial: reflexiones para una diversidad epistémica más allá del capitalismo global. Bogotá: Siglo del Hombre Editores, p. 79-91, 2007.

Castro Herrera, G. Naturaleza, sociedad e historia en América Latina. In: Alimonda, H. (Coord.). Ecología política - Naturaleza, sociedad y utopia. Bueno Aires: CLACSO, Consejo Latinoamericano de Ciencias Sociales, p. 38-99, 2002.

Espinoza, R. F. Rivalidade entre os polos: a construção discursiva do Conselho Mundial da Água. São Carlos, Tese (Doutorado em Sociologia) - UFSCar, 2016.

Frome, M. Green Ink: uma introdução ao jornalismo ambiental. Curitiba: Editora UFPR, 2008.

Gil, A. C. Como elaborar projetos de pesquisa. São Paulo: Atlas, 4. ed.,2002.

Girardi, I. M. T. Um semestre muito especial: o surgimento da primeira disciplina de jornalismo ambiental. In: Girardi, I. M. T.; Moraes, C. H.; Loose, E. B.; Belmonte, R. V. (Orgs.). Jornalismo ambiental - teoria e prática. Porto Alegre: Editora Metamorfose, p. 13-24, 2018.

Girardi, I. M. T.; Loose, E. B..; Almeida da Silva, J. Aturá Revista Pan-Amazônica de Comunicação, 2(2), 48-66, 2018.

Girardi, I. M. T.; Loose, E. B..; Sirena, M.; Pedroso, R. N. Jornalismo ambiental na construção da cidadania. In: Morigi, V.; Girardi, I. M. T.; Almeida, C. (Eds.). Comunicação, informação e cidadania. Porto Alegre: Sulina, p. 107-118, 2011.

Girardi, I. M. T.; Massierer, C..; Loose, E. B..; Schwa$\mathrm{ab}, \mathrm{R}$. Jornalismo ambiental: caminhos e descaminhos. Comunicação e sociedade, 34(1), 131-152, 2012. doi: 10.15603/2175-7755/cs.v34n1p131-152

Green, L. Fracking, oikos and omics in the Karo: reimagining South Africa's reparative energy policy. In: Anais do Colóquio Internacional Os mil nomes de Gaia. Rio de Janeiro, de 15 à 19 set., 2014. Disponível em: <https:// osmilnomesdegaia.files.wordpress.com/2014/11/lesleygreen.pdf>. Acesso em: mar 2020.

Kovach, B.; Rosenstiel, T. Os elementos do jornalismo - o que os profissionais do jornalismo devem saber e o público deve exigir. Porto: Porto Editora, 2004.

Lander, E. Ciências sociais: saberes coloniais e eurocêntricos. In: Lander, E. (Org.). A colonialidade do saber: eurocentrismo e ciências sociais - perspectivas latinoamericanas. Buenos Aires, Argentina: CLACSO, p.8-23, 2005.

Leff, E. Epistemologia ambiental. São Paulo: Editora Cortez, 2001.

Leff, E. Complexidade, racionalidade ambiental e diálogo de saberes. Revista Educação e Realidade, 34(3), 17-24, 2009. Disponível em: https://seer.ufrgs.br/educacaoerealidade/ article/view/9515

Leff, E. A aposta pela vida - Imaginação sociológica e imaginários sociais nos territórios ambientais do Sul. Petrópolis- RJ: Vozes, 2016.

Loose, E. B.; Maeve Sobrinho, Í. Jornalismo ambiental e humanizado: discutindo propostas para transformar a prática. In: Memorias del XIV Congreso de la Asociación 
Latinoamericana de Investigadores de la Comunicación. Costa Rica, 30 jul. - 1 ago., 2018.

Loose, E. B.; Souza-Lima, J. E. (Re)configurações do campo comunicacional a partir da epistemologia ambiental. Acta Scientiarum - Human and Social Sciences, 35(1), 61-70, 2013. doi: 10.4025/actascihumansoc.v35i1.19709

Maldonado-Torres, N. La descolonización y el giro des-colonial. Comentario Internacional, 7, 65-78. 2007. Disponível em: https://revistas.uasb.edu.ec/index-.php/comentario/ article/view-/130

Martins, R. C.; Espinoza, R. F.. Colonialidade e efeitos de verdade sob a perspectiva ambiental. Contemporânea, 8(1), 83-109, 2018. Disponível em: http://www.contemporanea. ufscar.br/index.php/contemporanea/article/view/657

Meditsch, E. O jornalismo é uma forma de conhecimento?. Biblioteca Online de Ciências da Comunicação da Universidade da Beira Interior, 1997. Disponível em: <http://www. bocc.ubi.pt/pag/meditsch-eduardo-jornalismo-conhecimento.pdf>. Acesso em: jun. 2020.

Mendes Pereira, L. H. Jornalismo e meio ambiente: possibilidades e dificuldades da informação como tradutora de uma política ambiental democrática. Revista Brasileira de Políticas de Comunicação, 5, 1-21, 2014.

Mignolo, W. D. Colonialidade: o lado mais escuro da modernidade. Revista Brasileira de Ciências Sociais, 32 (94), 1-18, 2017. doi: 10.17666/329402/2017

Oliveira, D. de. Jornalismo e emancipação - Uma prática jornalística baseada em Paulo Freire. Curitiba: Appris, 2017.

Porto-Gonçalves, C. W. Apresentação da edição em português. In: Lander, E. (Org.). A colonialidade do saber: eurocentrismo e ciências sociais - perspectivas latinoamericanas. Buenos Aires, Argentina: CLACSO, p. 3-5, 2005.

Porto-Gonçalves, C. W. A globalização da natureza e a natureza da globalização. Rio de Janeiro, Civilização Brasileira, 2006.

Sierra Caballero, F. Comunicación y buen vivir. Nuevas matrices teóricas del pensamiento latino-americano (editorial). Revista Latinoamericana de Comunicación Chasquí, 131, 09-18, 2016. doi: 10.16921/chasqui.v0i131.2899
Sousa Santos, B. Para uma sociologia das ausências e uma sociologia das emergências. Revista Crítica de Ciências Sociais, 63, 237 -280, 2002. Doi: 10.4000/rccs.1285

Sousa Santos, B. Para além do conhecimento abissal: das linhas globais a uma ecologia dos saberes, Revista Crítica de Ciências Sociais, 78, 3-46, 2007. doi: 10.1590/S010133002007000300004

Sousa Santos, B. Para além do conhecimento abissal: das linhas globais a uma ecologia dos saberes. In: Sousa Santos, B.; Meneses, M. P. (Orgs.). Epistemologias do sul. São Paulo: Cortez, p.31-83, 2010.

Sousa Santos, B.; Meneses, M. P. (Orgs.). Epistemologias do sul. São Paulo: Cortez, 2010.

Swampa, M. As fronteiras do neoextrativismo na América Latina - Conflitos socioambientais, giro ecoterritorial e novas dependências. São Paulo: Elefante, 2019.

Tornel, C. Introducción. In: Tornel, C. (coord.). Alternativas para limitar el calentamiento global en 1.5C-Más allá de la economía verde. Ciudad de México: Fundación Heinrich Böll, p.27-83, 2019.

Torrico Villanueva, E. R. A comunicação decolonial, perspectiva in/surgente. Revista Latinoamerica de Ciencias de la Comunicación, 15(28), 72-81, 2018. Disponível em: https:// www.alaic.org/revista/index.php/alaic/article/view/1150

Traquina, N. Teorias do jornalismo: a tribo jornalística uma comunidade interpretativa transnacional. Florianópolis: Insular, 2005.

Unger, N. M. O encantamento do mundo: ecologia e espiritualidade. São Paulo: Edições Loyola, 1991.

Unger, N. M. Da foz à nascente - O recado do rio. São Paulo: Editora Cortez, 2001.

Valencia Rincon, J. C. Mediaciones, comunicación y colonialidad: encuentros y desencuentros de los estudios culturales y la comunicación en Latinoamérica. Signo y Pensamiento, 30(60), 156-165, 2012. Disponível em: https:// revistas.javeriana.edu.co/index.php/signoypensamiento/ article/view/2417/170 